\title{
Intergenic Interactions and Hyperplastic Diseases of Endo- and Myometrium
}

\author{
${ }^{1}$ Irina V. Ponomarenko, ${ }^{2}$ Vladimir F. Kulikovskiy, ${ }^{3}$ Evgeny N. Krikun, ${ }^{4}$ Alexander A. Dolzhikov, ${ }^{5}$ Mikhail I. \\ Churnosov \\ Belgorod State University, 308015, Belgorod, Pobeda Street, 85, Russia \\ Email: Ponomarenko_i@bsu.edu.ru
}

\section{Received: 22 ${ }^{\text {nd }}$ June 2018, Accepted: 01 ${ }^{\text {st }}$ August 2018, Published: $31^{\text {st }}$ August 2018}

\begin{abstract}
This paper presents the results of bioinformatic analysis of three polymorphic loci in 170 women who suffer from a combination of uterine fibroids with endometrium hyperplastic processes and in 981 women of the control group without proliferative diseases of pelvic organs. It was found that the combinations of molecular genetic markers $\mathrm{C}$ rs673220, A rs4986938 и G rs887912 (OR=1.70) are risk factors for the development of a combination of endometrial hyperplasia and uterine myoma among women of the Central region of Russia.
\end{abstract}

Keywords: Hyperplastic Processes of the Endometrium, Uterine Myoma, Combined Pathology, Genetic Polymorphism.

\section{Introduction}

Among the gynecological incidence, the hyperplastic processes of the endometrium occupy a leading place and amount to 10-50\% [Boyraz G. et al., 2016]. Endometrial hyperplasia is a pathological process affecting the epithelial and stromal components of the endometrium and is manifested by an increase in the total number of glands [Clement N.S. et al., 2016]. Atypical endometrial hyperplasia is a precancerous condition, which can cause the development of endometrial cancer in $15-45 \%$ of cases [Kadirogullari P. et al., 2015]. The risk of development of endometrial cancer in women increases significantly with age and ranges from 5 to $10 \%$ [Kim M.-J. et al., 2016].

Uterine myoma is a benign monoclonal tumor composed of the smooth muscle cells of the myometrium. The prevalence of uterine fibroids ranges from $5 \%$ to $65 \%$, depending on age, ethnicity, geographic region and diagnostic method [Gurusamy K.S. et al., 2016]. According to the literature, uterine fibroids are most often observed in women of reproductive age (about 40\%) [Khan A.T. et al., 2014] and reaches a peak at 50 years [Zimmermann A. et al., 2012]. According to various data, surgical interventions are performed in $25-50 \%$ of women diagnosed with uterine myoma [Gurusamy K.S. et al., 2016].
According to literature data, the combination of endometrial hyperplasia with uterine myoma occurs in $30-35 \%$ of patients, due to the common etiology, risk factors and key pathogenetic links [Tan N. et al., 2014]. The well-known risk factors for the development of proliferative diseases of the uterus include age, early menarche, late menopause, absence of pregnancy in history, obesity, diabetes, family history, lifestyle, etc. [Segars J.H. et al., 2014; Chandra V. et al., 2016]. The leading premium in the etiopathogenesis of hyperplastic processes of the endometrium and uterine myoma is set on excessive estrogen stimulation, hormone-independent proliferation, inflammation, reduced apoptosis, pathological neoangiogenesis, and cytogenetic disorders [Segars J.H. et al., 2014; Chandra V. et al., 2016].

The combined development of these diseases is of great clinical importance, since it raises significant difficulties in diagnosing and choosing the most effective method of treatment. In addition, it leads to a decrease in the quality of life of a woman.

Now it is known that polymorphisms of several genes are important in the formation of disposition to the development of hyperplastic diseases of uterus [Edwards T.L. et al., 2013; Krivoshei I.V. et al., 2015; Orbo A. et al., 2016; Pachomov S.P. et al., 2016; Ponomarenko, I.V. et al., 2016]. However, the results of studies on the role of candidate genes in the formation of hyperplastic processes of the endometrium and uterine myoma are controversial in different populations.

Objective of the research was a bioinformatic study of the involvement of three genetic polymorphisms (rs887912, rs6732220, rs4986938) in the development of a combination of endometrium hyperplastic processes with uterine myoma in women of the Central region of Russia.

\section{Materials and Methods}

In this study, patients with a combination of uterine myoma and endometrial hyperplasia $(n=170)$ were selected from a group of 947 patients with various uterine hyperplastic processes. The sample was made on the basis of the gynecological department of the perinatal center of St. Joasaph Belgorod Regional 
Clinical Hospital. Patients with a combination of uterine myoma and endometrial hyperplasia underwent a clinical, clinical and laboratory examination, ultrasound examination of pelvic organs, hysteroscopy followed by targeted diagnostic scraping of the uterine cavity and histological examination of scrapings. All patients signed an informed consent for inclusion in the study and use of the data obtained. The control group involved 981 women without proliferative diseases of the pelvic organs.

All patients with endometrial hyperplasia and uterine myoma were performed typing of three moleculargenetic markers rs887912 FLJ30838, rs6732220 FSHR, rs4986938 ESR2. The choice of these polymorphic markers for the study is due to their significant regulatory and expression potential (HaploReg (v.4.1.) (http://compbio.mit.edu/HaploReg)) and the important ethiopathogenetic significance of these genes for hyperplastic uterine disease [Commandeur A.E. et al., 2015].

As the material for the study we used 8-9 $\mathrm{ml}$ of venous blood taken from the cubital vein of a proband. A genomic DNA was isolated from peripheral blood by the method of phenol-chloroform extraction (Mathew C.G., 1985). Analysis of the investigated loci was carried out by the method of polymerase chain reaction of DNA synthesis with the use of oligonucleotide primers and probes.

Statistical processing of data was carried out using STATISTICA for Windows 6.0 and Microsoft Excel 2007 software packages. To analyze the compliance of the observed distribution of genotypes with the expected one, based on Hardy-Weinberg equilibrium, we used $\chi^{2}$ test.

A bioinformatic study was performed by APSampler [http://sources.redhat.com/cygwin/], operating Markov chain Monte Carlo, and Bayesian nonparametric statistics [Favorov A., 2011].

\section{Results and Discussion}

We examined 170 female patients with the combination of uterine myoma and endometrial hyperplasia, and 981 women of the control group. The main characteristics of the study and control groups are shown in Table 1. The control group is fully comparable to the sample of patients with the combination of uterine myoma and endometrial hyperplasia by age, ethnicity, and place of birth.

\begin{tabular}{|l|l|l|}
\hline Characteristics & Cases & Controls \\
\hline Total & 170 & 981 \\
\hline Age, yrs & $45.06 \pm 8.23$ & $39.94 \pm 9.31$ \\
\hline Height, cm & $1.66 \pm 0.07$ & $1.65 \pm 0.06$ \\
\hline Weight, kg & $77.09 \pm 14.50$ & $69.69 \pm 12.49$ \\
\hline IMB & $28.10 \pm 5.80$ & $25.69 \pm 4.24$ \\
\hline
\end{tabular}

Table 1 Characteristics of the Subjects from the Case and Control Groups.

The analysis of the distribution of studied polymorphic markers of candidate genes showed that for all the studied loci in the group of patients with the combination of uterine myoma and endometrium hyperplastic processes, as well as in the control sample, the empirical distribution of genotypes corresponds to the theoretically expected one at Hardy-Weinberg equilibrium ( $\mathrm{p}>0.05)$.

As a result of the bioinformatic analysis, significant differences in the concentrations of $\mathrm{C}$ alleles rs673220 with A rs4986938 with G rs887912 were found among the patients with a combination of endometrial hyperplasia and uterine myoma $(62.87 \%)$ and the control group (49.84\%). This combination of allelic variants is a risk factor for the development of endometrial hyperplasia and uterine myoma $(\mathrm{p}=0.001$, $\mathrm{p}_{\text {perm }}=0.011, \mathrm{OR}=1.70,95 \%$ CI 1.21-2.39).

Using HaploReg (v.4.1.) online service (http://compbio.mit.edu/HaploReg), the regulatory potential and the influence on the expression of genes of significant polymorphisms associated with the combination of endometrial hyperplasia and uterine myoma were studied. The genetic polymorphism rs6732220, localized in the intron portion of the FHSR gene, affects the transcription activity of this gene in the testes $(p=2.81 \mathrm{E}-08)$. It participates in the development of menarche age $(p=0.0018)$ [Lappalainen T. et al., 2013].

The genetic polymorphism rs887912, located $12 \mathrm{~kb}$ from the 3' end of the FLJ30838 gene has a high regulatory and expressive potential and marks histone proteins within the enhancers. It should be noted that $G$ allele (as part of the three combinations increases the risk of hyperplastic processes of the endothelium and uterine myoma) increases the affinity of the DNA motif - Hoxa5_1 (PWM =-0.6), while its reference A allele is associated with increased affinity of the Znf143_known1 motif (PWM=1.0). This genetic polymorphism is associated with a body mass index $(\mathrm{p}=2 \mathrm{E}-22) \quad$ [Speliotes E.K. et al., 2010] and anthropometric characteristics at pubertal age $(p=1 \mathrm{E}-$ 10) [Berndt S.I. et al., 2013] and the age of menarche [Fernandez-Rhodez L. et al., 2013].

The polymorphic locus rs4986938, located in 3 ' of the end of the ESR2 gene, marks histone proteins in the region of promoters in the cerebral cortex and blood cells. It affects the expression level of the ESR2 gene in the left ventricle of the heart $(\mathrm{p}=9.99 \mathrm{E}-07)$, skin cells $(p=3.86 \mathrm{E}-08)$ [Ardlie K.G. et al., 2015] and lymphoblast cells ( $\mathrm{p}=3.65 \mathrm{E}-10)$ [Lappalainen T. et al., 2013]. It should be noted that this gene is most actively expressed in testes (RPKM: 1.79 \pm 0.27 ), adrenal glands (RPKM: $1.09 \pm 0.28$ ), ovaries (RPKM: 0.60 \pm 0.09 ), lymph nodes (RPKM: 0.42 \pm 0.21 ), adipose 
tissue (RPKM: $0.48 \pm 0.04$ ). This genetic polymorphism is part of five DNA motifs. At the same time, the "risky" A allele increases the affinity of the regulatory motif CTCF_known1 (PWM=0.6), Pax6_1 (PWM=11.1), RAR (PWM=0.1).

\section{Conclusion}

Thus, the results of the study allow us to conclude that the combinations of molecular genetic markers $\mathrm{C}$ rs673220, A rs4986938 и G rs887912 (OR=1.70) are risk factors for the development of a combination of endometrial hyperplasia and uterine myoma among women of the Central region of Russia.

\section{References}

1. Ardlie, K.G., Deluca, D.S., Segrè, A.V., Sullivan, T.J., Young T.R., 2015. Human genomics. The Genotype-Tissue Expression (GTEx) pilot analysis: multitissue gene regulation in humans. Science, 348(6235):648-60. doi: 10.1126/science. 1262110 .

2. Berndt, S.I., Gustafsson, S., Mägi, R., Ganna, A., Wheeler, E., Feitosa, M.F., 2013. Genomewide meta-analysis identifies 11 new loci for anthropometric traits and provides insights into genetic architecture. Nat Genet., 45(5): 501-512. doi: 10.1038/ng.2606.

3. Boyraz, G., Başaran, D., Salman, M.C., Özgül N., Yüce K., 2016. Does Preoperative Diagnosis of Endometrial Hyperplasia Necessitate Intraoperative Frozen Section Consultation? 33(6):657-661. doi: 10.5152/balkanmedj.2016.151232.

4. Chandra, V., Kim, J.J., Benbrook, D.M., Dwivedi, A., Rai, R., 2016. Therapeutic options for management of endometrial hyperplasia. J Gynecol Oncol, 27(1):e8. doi: $10.3802 /$ jgo.2016.27.e8.

5. Clement, N.S., Oliver, T.R., Shiwani H., Saner, J.R. , Mulvaney, C.A., Atiomo, W., 2016. Metformin for endometrial hyperplasia: a Cochrane protocol. BMJ Open, 6(8):e013385. doi: 10.1136/bmjopen-2016-013385.

6. Commandeur, A.E., Stye,r A.K., Teixeira, J.M., 2015. Epidemiological and genetic clues for molecular mechanisms involved in uterine leiomyoma development and growth. Hum Reprod Update, 21(5):593-615. doi: 10.1093/humupd/dmv030.

7. Edwards, T.L., Michels, K.A., Hartmann, K.E., Digna, R., 2013. BET1L and TNRC6B associate with uterine fibroid risk among European Americans. Hum Genet. 132(8):943953. doi: 10.1007/s00439-013-1306-3.

8. Favorov, A., Lvovs, D., Speier, W., 2011. Onion Tree XML: A Format to Exchange Gene-
Related Probabilities. Biomol. Struct. Dyn., 29(2):417-423.

doi: 10.1080/073911011010524994

9. Fernandez-Rhodez, L., Demerath, E.W., Cousminer, D.L., Tao, R., Dreyfus, J.G., Esko, T., Smith, A.V., Gudnason, V., 2013. Association of Adiposity Genetic VariantsWith Menarche Timing in 92,105 Women of European Descent. American Journal of Epidemiology, 1-10. doi:10.1093/aje/kws473.

10. Gurusamy, K.S., Vaughan, J., Fraser, I.S., Best, L.M., Richards, T., 2016. Medical Therapies for Uterine Fibroids - A Systematic Review and Network Meta-Analysis of Randomised Controlled Trials. PLoS One, 11(2):e0149631. doi: 10.1371/journal.pone.0149631.

11. Kadirogullari, P., Atalay, C.R., Ozdemir, O., Erkan, M., 2015. Sari Prevalence of Coexisting Endometrial Carcinoma in Patients with Preoperative Diagnosis of Endometrial Hyperplasia. Clin. Diagn. Res., 9(10):QC10QC14. doi: 10.7860/JCDR/2015/12484.6618.

12. Khan, A.T, Shehmar, M., Gupta, J.K., 2014. Uterine fibroids: current perspectives. Womens Health, 6:95-114. doi: 10.2147/IJWH.S51083.

13. Kim, M.-J., Kim, J.-J., Kim, S.M., 2016. Endometrial evaluation with transvaginal ultrasonography for the screening of endometrial hyperplasia or cancer in premenopausal and perimenopausal women. Obstet Gynecol Sci., 59(3):192-200. doi: 10.5468/ogs.2016.59.3.192.

14. Krivoshei, I.V., Altuchova, O.B., Golovchenko, O.V., Orlova, V.S., Polonikov, A.V., Churnosov, M.I., 2015. Genetic factors of hysteromyoma. Research Journal of Medical Sciences, 9(4):182-185.

15. Lappalainen, T., Sammeth, M., Friedländer, M.R., Hoen, P.A., Monlong, J., Rivas, M.A., 2013. Transcriptome and genome sequencing uncovers functional variation in humans. Nature, 501(7468):506-11. doi: 10.1038/nature12531.

16. Mathew, C.G, 1985. The isolation of high molecular weight eukaryotic DNA Methods. Mol. Biol., 2: 31-34.

17. Orbo, A., Arnes, M., Vereide, A.B., Straume, B., 2016. Relapse risk of endometrial hyperplasia after treatment with the levonorgestrel impregnated intrauterine system or oral progestogens. BJOG, 123(9):1512-1519. doi: 10.1111/1471-0528.12499.

18. Pachomov, S.P., Ponomarenko, I.V., Kulikovskiy, V.F., Orlova, V.S., Krikun, E.N., Sorokina, I.N., Batlutskaya, I.V., Bushueva, O.Y., 2016. Analysis of Candidate Genes for Uterine Fibroids. Research Journal of Pharmaceutical, 
Biological and Chemical Sciences, №7(6): 32393242.

19. Ponomarenko, I.V., Altuchova, O.B., Golovchenko, O.V., Sorokina, I.N., Polonikov, A.V., Bushueva, O.Y., Churnosov, M.I., 2016. Molecular-genetic factors of genital endometriosis. International Journal of Pharmacy and Technology, 8(2): 14190-14195.

20. Segars, J.H., Parrott, E.C., Nagel, J.D., Guo, X.C., Gao, X.,. Birnbaum, L.S., Pinn, V.W., Dixon ,D., 2014. Proceedings from the Third National Institutes of Health International Congress on Advances in Uterine Leiomyoma Research: comprehensive review, conference summary and future recommendations. Hum Reprod Update, 20(3):309-333. doi: 10.1093/humupd/dmt058.

21. Speliotes, E.K., Willer, C.J., Berndt, S.I., Monda, K.L., Thorleifsson, G., Jackson A.U., 2010. Association analyses of 249,796 individuals reveal 18 new loci associated with body mass index. Nat Genet., 42(11):937-48. doi:10.1038/ng.686.

22. Tan, N., Clure, T.D., Tarnay, C., Johnson, M.T., Lu, D., Raman, S.S., 2014. Women seeking second opinion for symptomatic uterine leiomyoma: role of comprehensive fibroid center. Ther Ultrasound, 2. Available at: http://www.ncbi.nlm.nih.gov/pmc/articles/PMC4 265989/ (accessed 15.04.2014). doi: 10.1186/2050-5736-2-3.

23. Zimmermann, A., Bernuit, D., Gerlinger, C., Schaefers, M., Geppert, K., 2012. Prevalence, symptoms and management of uterine fibroids: an international internet-based survey of 21,746 women. BMC Womens Health, 12:6. doi: 10.1186/1472-6874-12-6. 